\title{
Study protocol: Determinants of participation and quality of life of adolescents with cerebral palsy: a longitudinal study (SPARCLE2)
}

\author{
Allan F Colver*1,2, Heather O Dickinson ${ }^{1}$ and SPARCLE group*
}

\begin{abstract}
Background: Children and adults with impairments such as cerebral palsy have lower participation in life situations than able-bodied people. Less is known about their subjective perception of their lives, called their quality of life.

During adolescence, rapid physical and psychological changes occur; although these may be more difficult for disabled than for able-bodied adolescents, little research has examined the lives of disabled adolescents.

In 2003-4 a European Union funded project, SPARCLE, visited 818 children aged 8-12 years with cerebral palsy, sampled from population-based registers in nine European regions. The quality of life reported by these disabled children was similar to that of the general population but their participation was lower; levels of participation varied between countries even for children with similar severity of cerebral palsy.

We are currently following up these children, now aged 13-17 years, to identify (i) to what extent contemporaneous factors (pain, impairment, psychological health and parental stress) predict their participation and quality of life, (ii) what factors modify how participation and quality of life at age 8-12 years are associated with participation and quality of life in adolescence, and (iii) whether differences between European countries in participation and quality of life can be explained by variations in environmental factors.

Methods/Design: Trained researchers will visit families to administer questionnaires to capture the adolescents' type and severity of impairment, socio-demographic characteristics, participation, quality of life, psychological health, pain, environmental access and parental stress. We will use multivariable models (linear, logistic or ordinal) to assess how adolescent participation, quality of life, psychological health, pain, environmental access and parental stress, vary with impairment and socio-demographic characteristics and, where possible, how these outcomes compare with general population data. For participation and quality of life, longitudinal analyses will assess to what extent these are predicted by corresponding levels in childhood and what factors modify this relationship. Structural equation modelling will be used to identify indirect relationships mediated by other factors.
\end{abstract}

\section{Background}

Children with impairments such as cerebral palsy are significantly disadvantaged;[1] in adulthood they continue to be disadvantaged with respect to employment and social relationships $[2,3]$.

Much is now understood about factors which contribute to the disadvantage of young disabled children: many of the factors, such as services, support and physical

\footnotetext{
* Correspondence: allan.colver@ncl.ac.uk

${ }^{1}$ Institute of Health and Society, Newcastle University, Newcastle upon Tyne, UK

Full list of author information is available at the end of the article
}

aspects of the environment, are mediated through the family [4]. Far less is known about the teenage years; in particular there has been little attempt to unravel how the physical and psychological changes of adolescence are influenced by the person's impairments. Also there is little understanding of how participation and quality of life evolve as a child grows older, or how factors in childhood enable some disabled teenagers to adapt better than others. 


\section{Conceptual framework}

The Social Model of Disability [5] regards disability as resulting from the interaction between the individual and their environment rather than as intrinsic to the individual. The International Classification of Functioning, Disability and Health (ICF) [6], and its modification for children and young people ICF-CY [7] provide a powerful framework for operationalising this model. They define participation as involvement in life situations and examples of its nine domains are communication, domestic life and community life. Participation may be affected by the individual's impairments, their consequent activity limitations and contextual factors, both environmental and personal.

Formerly, concepts of quality of life (QoL) overlapped with those of handicap, function and activities of daily living [8]. QoL is now generally regarded as a subjective, self-reported concept [9]. WHO defines QoL as "an individual's perception of their position in life in the context of the cultural and value systems in which they live, and in relation to their goals, expectations, standards and concerns" [10].

The concepts of participation and QoL apply to everyone and it is especially important that they are considered for disabled people so that their needs, assessments and assistance are considered in the same framework as all people. Our own studies, Appendix paragraphs 1 and 5 and [11], show that lower QoL is only weakly related to severity of impairment whereas restricted participation is strongly related. Participation and QoL must therefore be assessed as separate but equally important outcomes the former being objective, the latter subjective.

\section{Disabled adolescents}

Adolescence is a developmental phase between childhood and adulthood that may last beyond age twenty [12]. A number of transitions occur such as moving from shared decision-making with parents to self-reliance; or from economic dependence to paid employment [13]. The adjustment is always challenging and often difficult, especially for disabled adolescents. Parents and care-givers may also find this time difficult as their role in the young person's life and their relationship with them changes. Growth and puberty will also interact with impairments; for example incontinence, previously tolerated, may adversely affect body image and emerging sexuality.

Health services for adolescents are recognised as inadequate [14-16]. As disabled adolescents move to care by adult teams, the holistic approach of child health, education and social services may be lost and available resources may be limited [17]. This may exacerbate a young person's psychological vulnerability.

\section{Participation and QoL of adolescents with cerebral palsy}

Adolescents with cerebral palsy (CP) have a range of type and severity of impairments; in addition to problems with movement or posture, they usually have one or more additional impairments of vision, hearing, intellect, communication or behaviour. Some impairments may lead to secondary problems such as contractures, joint dislocation or chest infections. By studying adolescents with such a range of impairments, results can be generalised to disabled adolescents with other underlying conditions.

Adolescents with CP may be limited in their ability to participate fully in many school activities and social life compared with able-bodied peers $[14,18]$. The adolescent's participation may be affected by their type of CP and associated impairments $[19,20]$. Our studies show 812-year-old children with more severe impairments have lower participation (Appendix paragraph 5). Normal peer interactions, such as gossiping, fooling around and finding one's own solutions to problems may be prevented by the high level of adult surveillance experienced by some disabled children [21]. Pain is common in CP and is associated with lower participation Appendix paragraph 5 and [22] but the origins of the pain have not been studied systematically. Environmental barriers to participation include psychosocial pressures from family, school and community, financial difficulties, inadequate public services and physical barriers [23].

Studies of QoL of adolescents with CP give conflicting results, largely due to inadequate study design or because measures of function, mistakenly called and believed to be QoL, were used [24,25]. Our study of QoL of 8-12 year old children with CP showed that, on average, the QoL of those able to self-report was similar to that of the general population [11]. Although some impairments were associated with poorer QoL in some areas of their lives, their QoL was determined largely by other factors. It is not known whether QoL of children with CP changes as they reach adolescence but QoL of adolescents in the general population is reportedly lower than that of children, this effect being more marked in girls [26].

\section{The way forward}

Our study aims to identify determinants of participation and QoL amenable to intervention and should therefore provide evidence to inform trials of interventions. Pain can be alleviated, psychological interventions can improve child mental health and parental stress; and the physical and social environment can be modified. We expect adolescent participation and QoL to be strongly predicted by corresponding scores in childhood; however, we will seek to identify the factors which modify this relationship, e.g. those factors associated with unfavourable outcomes in adolescents who had favourable outcomes in childhood. 
Our specific objectives are to investigate in adolescents with cerebral palsy across Europe:

- How their participation and QoL compare with that of the general population and what factors predict differences.

- To what extent pain, impairment, psychological health and parental stress (all amenable to intervention) predict participation and QoL.

- What factors modify how participation and QoL at age 8-12 years are associated with participation and QoL in adolescence.

- Whether there are differences between European countries in participation and QoL; if so, whether these can be explained by variations in environmental factors.

\section{Basis for this collaboration and background work already conducted}

This collaborative study builds on a programme of research undertaken by the SPARCLE group in nine European regions since 2000:

- Eight of these regions run a population-based register of children with cerebral palsy covering a defined geographical area. These regions belong to a collaboration funded by the European Union's Biomed 2 BMH4-983701 and DG SANCO QLG5-CT-200130133 and have reported on the epidemiology of CP across Europe [27]. The UK registers [28] have reported on life expectancy of people with $\mathrm{CP}$ in a study funded by the Medical Research Council [29].

- The SPARCLE group undertook a research project [30] funded by EU Research Framework 5 RF5 QLG5CT-2002-00636 called "The influence of environmental factors on the participation and QoL of 8-12-yearold children with cerebral palsy in 9 European regions" and led by AC [11,23,30-47]. The main findings are summarised in Appendix 1 and full details of results and publications are located at http:// www.ncl.ac/sparcle.

\section{Methods/Design}

The primary design is a follow-up survey of 13-17-yearolds with CP from nine European regions. The children were randomly sampled from population-based registers, using an agreed classification of CP [27], at 8-12 years old when baseline data were gathered.

\section{Sample}

The SPARCLE1 sample was established when the children were visited at 8-12 years [30,31]. In summary, 818 children born between 31st July 1991 and 1st April 1997 were visited, after sampling from eight population-based registers of children with cerebral palsy in six European countries. One further region recruited 75 children from multiple sources. The response rate of $63 \%$ was similar to that in surveys of similar design which target specific families and conduct face-to-face interviews [48]. In larger regions, sampling was stratified to ensure adequate numbers of children of all levels of impairment.

In order to minimise attrition, maximum effort will be made to re-interview every young person recruited for SPARCLE1, even if they have moved out of area. Nevertheless, on the basis of longitudinal cohort studies of children [49], we anticipate attrition of around $20 \%$, yielding an achieved sample of about 650 participants across the nine regions, of whom 400 could self-report.

In order to maintain statistical power for cross-sectional analyses and possible further follow-up in adulthood, we will additionally sample from adolescents eligible for SPARCLE1, but not sampled then, in order to achieve a sample size similar to SPARCLE1. Assuming a non-response rate as in SPARCLE1, 270 further adolescents will need to be approached.

\section{Power calculation}

The SPARCLE1 sample of 818 children had substantial statistical power: it allowed detailed multivariable models relating QoL and participation to psychological health, parental stress, impairment and socio-demographic factors $[11,32,42,50,51]$.

Power calculations indicate that, in order to detect a difference of half a standard deviation (regarded as clinically important) between two sub-groups, at $90 \%$ power and $1 \%$ significance, we would require 120 adolescents in each group. A smaller sample of 90 adolescents in each group would be adequate if baseline (childhood) values were used as covariates, assuming a correlation of 0.5 between childhood and adolescent scores. Hence we anticipate that the achieved sample should be adequate to detect differences between major sub-groups of children, in both cross-sectional and longitudinal analyses; and even if comparisons are restricted to self-reporting children. Furthermore, even if there was $30 \%$ attrition at random, confidence intervals for multivariable models of factors associated with QoL of self-reporting children [11] would increase by about $20 \%$, but all factors previously significant at the $\mathrm{p}<0.01$ level would remain significant at $\mathrm{p}<0.05$. For effective structural equation modelling with two to four factors, the recommended sample size is at least 200 [52], a sample size which again would be achieved among self-reporting children.

\section{Training of RAs}

An RA will be appointed in each region to revisit the SPARCLE1 children, now adolescents aged 13-17 years. The RAs will attend a training workshop (see Table 1) to ensure quality, consistency between centres and motivation. Instruction will include the rationale for the study, 
Table 1: Project timetable: milestones and workshops

\begin{tabular}{|c|c|c|}
\hline MILESTONES & Description & Month \\
\hline 1 & Ethics permissions in place & 2 \\
\hline 2 & $\begin{array}{l}\text { Completion of training of RAs and their } \\
\text { pilot visits }\end{array}$ & 4 \\
\hline 3 & $\begin{array}{l}\text { Completion of agreed protocols for data } \\
\text { analysis }\end{array}$ & 14 \\
\hline 4 & Completion of visits to adolescents & 14 \\
\hline 5 & $\begin{array}{l}\text { Completion of data cleaning and scoring } \\
\text { of questionnaires }\end{array}$ & 16 \\
\hline 6 & $\begin{array}{l}\text { Completion of development of analysis } \\
\text { programs and testing on sample of data }\end{array}$ & 18 \\
\hline 7 & $\begin{array}{l}\text { Completion of initial analyses and drafts of } \\
\text { papers }\end{array}$ & 28 \\
\hline 8 & Completion of report & 30 \\
\hline WORKSHOPS & Description & \\
\hline 1 & Management group meeting & -3 \\
\hline 2 & Train RAs & 2 \\
\hline 3 & Further meeting of RAs after pilot visit & 4 \\
\hline 4 & $\begin{array}{l}\text { Share expertise in statistical methodology } \\
\text { and programs. }\end{array}$ & 18 \\
\hline 5 & $\begin{array}{l}\text { Finalise and agree results; scrutinise } \\
\text { preliminary papers }\end{array}$ & 28 \\
\hline
\end{tabular}

study design, how to engage adolescents and administer the questionnaires, disability issues, good clinical practice and ethical requirements of the Declaration of Helsinki [53]. Following this, each RA will undertake five pilot visits and a second training workshop will address any difficulties encountered.

\section{Visits}

The RAs will visit at venues to suit the adolescents and parents. The questionnaires are self-completed but the RA will explain them, answer queries that arise and, for adolescents with motor or communication difficulties, assist or bring a non-parental interpreter of sign language or unclear speech.

\section{Instruments}

As QoL concerns how a person perceives their life, it should be captured wherever possible by a self-report instrument, designed for and derived from work with the relevant age group. KIDSCREEN [54] is such an instrument developed from work with children and adolescents across Europe and used by the applicants in their earlier study $[11,32,42]$. Adolescents with severe learning difficulties (about one quarter of people with cerebral palsy) should be included in studies and their QoL inferred from reports by parents or other proxies.
For personal factors, we will capture: the adolescent's age, gender, psychological health and their self-efficacy or motivation, which is a distinct, concrete aspect of personality that has been well studied $[55,56]$ and postulated to be a determinant of participation and QoL.

For contextual factors we will capture: the school and community and family environment family environment, including parental stress. In families of disabled children, parental stress is higher, especially if the child is severely impaired; this stress is associated with lower QoL in their children [32,57].

Table 2 lists the proposed instruments, the concepts captured, the relevant age range and whether general population data are available for comparison. It also shows the links with SPARCLE1 instruments. Because we are interested primarily in predictors of adolescent outcomes (rather than magnitude of change in outcomes) and parent-reported child factors may be valid predictors of adolescent outcomes, it is not essential that instruments are the same as in SPARCLE1 or reported by the same person. Where adolescents can self-report, they will complete instruments; where they cannot, parents will.

Where adolescent and parent may have important different perspectives such as for psychological health [58], each will be asked to complete the instrument. The parent and adolescent view of QoL of those who can self- 
Table 2: Instruments to be used in SPARCLE2

\begin{tabular}{|c|c|c|c|c|}
\hline SPARCLE1 & SPARCLE2 & Captures & Domains & Comments \\
\hline Life-H $[64,65]$ & Same instrument & Participation & $\begin{array}{l}\text { Communication, Personal care, } \\
\text { Home life, mealtimes, Mobility, } \\
\text { Fitness, Recreation, Responsibility, } \\
\text { Education, Community Life, } \\
\text { Interpersonal relations }\end{array}$ & $5-20$ years \\
\hline $\begin{array}{l}\text { Frequency of } \\
\text { participation } \\
\text { questionnaire [51] }\end{array}$ & $\begin{array}{l}\text { Modified } \\
\text { instrument based } \\
\text { on qualitative } \\
\text { interviews with } \\
\text { adolescent }\end{array}$ & $\begin{array}{l}\text { Frequency of } \\
\text { discretionary } \\
\text { participation }\end{array}$ & $\begin{array}{l}31 \text { items: } \\
\text { Home life, Getting on with other } \\
\text { people, Education, Work and } \\
\text { finances, Community and political } \\
\text { life, Recreation and leisure, } \\
\text { Preparing for the future, }\end{array}$ & $\begin{array}{l}\text { 13-20 years } \\
\text { General population } \\
\text { data available }\end{array}$ \\
\hline KIDSCREEN [54] & Same instrument & Quality of life & $\begin{array}{l}\text { Psychological, Emotion, Social } \\
\text { support, Home life, Self perception, } \\
\text { Autonomy, School, Social } \\
\text { acceptance, Finance, Physical well- } \\
\text { being }\end{array}$ & $\begin{array}{l}\text { 8-18 years } \\
\text { Data available from } \\
\text { general population } \\
\text { with socio-economic } \\
\text { details }\end{array}$ \\
\hline $\begin{array}{l}\text { Strength and } \\
\text { Difficulties } \\
\text { Questionnaire (SDQ) } \\
\text { [58] }\end{array}$ & Same instrument & $\begin{array}{l}\text { Emotional } \\
\text { health and } \\
\text { behaviour }\end{array}$ & $\begin{array}{l}\text { Emotional symptoms } \\
\text { Conduct problems } \\
\text { Hyperactivity } \\
\text { Peer problems } \\
\text { Pro-social behaviour }\end{array}$ & $\begin{array}{l}\text { 8-16 years. But can be } \\
\text { used up to } 19 \text { years } \\
\text { (Goodman Personal } \\
\text { Communication) } \\
\text { General population } \\
\text { data available from } \\
\text { some countries but } \\
\text { socio-economic details } \\
\text { not available }\end{array}$ \\
\hline $\begin{array}{l}\text { Parenting Stress Index } \\
\text { Short Form (PSI-SF) } \\
{[66]}\end{array}$ & Same instrument & $\begin{array}{l}\text { Parental } \\
\text { stress }\end{array}$ & $\begin{array}{l}\text { Parental distress } \\
\text { Parent-child dysfunctional } \\
\text { interaction } \\
\text { Difficult child } \\
\text { PSI Life stress scale }\end{array}$ & $\begin{array}{l}\text { Data available from } \\
\text { general population } \\
\text { from all SPARCLE } \\
\text { countries but socio- } \\
\text { economic details not } \\
\text { available }\end{array}$ \\
\hline Impairment & Same descriptors & Impairments & $\begin{array}{l}\text { Type of cerebral palsy, Gross motor } \\
\text { function, Upper limb function, } \\
\text { Intelligence, Hearing, Vision, } \\
\text { Communication, Feeding Seizures }\end{array}$ & This is descriptive \\
\hline $\begin{array}{l}\text { Background young } \\
\text { person child and } \\
\text { family factors }\end{array}$ & Same descriptors & & $\begin{array}{l}\text { Age, Sex, School, Siblings, Partner } \\
\text { status, Parental educational } \\
\text { qualifications, Parental employment } \\
\text { status, Parental occupation }\end{array}$ & This is descriptive \\
\hline \multirow[t]{3}{*}{$\begin{array}{l}\text { Child Health } \\
\text { Questionnaire [67]. } \\
\text { Two questions on pain }\end{array}$} & Same questions & $\begin{array}{l}\text { Pain severity } \\
\text { and } \\
\text { frequency }\end{array}$ & & $\begin{array}{l}8-18 \text { years } \\
\text { Additional questions } \\
\text { asked about location } \\
\text { and cause of pain }\end{array}$ \\
\hline & $\begin{array}{l}\text { Pediatric Pain } \\
\text { Questionnaire [68] }\end{array}$ & Pain location & & 13-18 years \\
\hline & $\begin{array}{l}\text { Dimensions of } \\
\text { mastery } \\
\text { questionnaire [56] }\end{array}$ & $\begin{array}{l}\text { Motivation } \\
\text { and self- } \\
\text { efficacy }\end{array}$ & Total mastery score & $\begin{array}{l}\text { 14-18 years } \\
\text { Data available from } \\
\text { general population } \\
\text { but socio-economic } \\
\text { details not available }\end{array}$ \\
\hline $\begin{array}{l}\text { Environmental } \\
\text { questionnaire } \\
{[35,44] \text {. }}\end{array}$ & Same questions & $\begin{array}{l}\text { Availability of } \\
\text { environment } \\
\text { al factors } \\
\text { required to } \\
\text { facilitate } \\
\text { participation }\end{array}$ & $\begin{array}{l}\text { Physical home, Physical school, } \\
\text { Physical community, Transport, } \\
\text { Social support home, Social support } \\
\text { community, Attitudinal } \\
\text { schoolteachers and therapists, } \\
\text { Attitudinal classmates }\end{array}$ & 6-18 years \\
\hline
\end{tabular}


report will both be captured in order to facilitate inferences about the QoL of adolescents who cannot selfreport.

\section{Data management}

Photocopies of completed questionnaires will be sent to Newcastle for double entry on a dedicated database. Data entry and validation will be continuous so that problems will be identified and addressed immediately rather than becoming apparent on completion of data collection. Programmes - already written for questionnaires used in SPARCLE1 - will be run to check missing data, ranges of responses and consistency between regions.

\section{Data analysis}

In order to prevent bias due to "post hoc" analyses, protocols for statistical analysis will be pre-specified and agreed by month 14 , milestone 3 . Drop-out will be examined for relationships to observed factors such as age, gender, level of impairment and baseline levels of QoL, participation and parental stress [31]. As in SPARCLE1, the psychometric performance of the instruments (internal consistency, convergent/divergent validity, confirmatory factor analyses) will be compared with properties reported by their developers. For the adolescent's participation, QoL, psychological health and parental stress, domain scores will be compared with general population data, adjusting where possible for socio-demographic characteristics [11].

Figure 1 shows diagrammatically the essence of the model we shall use.

Whilst cross-sectional analyses will compare disabled adolescents with the general population of the same age, most analyses will utilise the strength of longitudinal design to understand not only the contemporaneous but also the childhood predictors of adolescent participation and QoL.

- A For the adolescent's participation, QoL, psychological health, pain, parental stress and environmental access, multivariable models (linear, logistic or ordinal) will be used to assess how scores on each domain vary with type and level of impairment, and adolescent and family socio-demographic characteristics $[11,32,50,51]$.

- B For participation and QoL, longitudinal analyses will assess to what extent these are predicted by corresponding scores in childhood and what factors modify this relationship. Sensitivity analyses will assess the possible effect of differential attrition [59]. These analyses will model the non-response mechanism on the basis of plausible values informed by clinical expertise, with weights corresponding to the inverse probability of non-response [60].
The models of participation and QoL generated by points $A$ and $B$ above will then be combined in unified models for each outcome using structural equation modelling (SEM). These will model the latent traits captured by the various instruments, (including the participation and QoL in childhood), to predict adolescent participation and QoL [61,62]. SEM can quantify both direct relationships between latent traits, the effects of factors that modify these relationships, and also indirect relationships mediated by other factors. Plausible models will be informed by clinical expertise. The longitudinal nature of the study, with data at two time points on each child, may facilitate identification of causal pathways [63].

Primary analyses will use Stata, based on programs written for SPARCLE1; SEM will use LISREL or Mplus.

\section{Project management}

The responsibility for delivering on all objectives lies with the project management group which will comprise the nine scientific leads, the senior research associate in Newcastle and statisticians in Newcastle and Toulouse. The group will meet during the project's workshops (see Table 1). AFC will co-ordinate the project.

The central co-ordination, data collation and much statistical analysis will take place in Newcastle, as in SPARCLE1.

An external advisory group will meet at the beginning of the project and soon after data analysis has begun to monitor progress. Membership will comprise a young adult with cerebral palsy, paediatrician with adolescent expertise, medical statistician, research paediatric orthotist and chief executive of a voluntary organisation.

\section{Ethics}

For those in SPARCLE1, we already have permission to contact the family for a further study. For those not approached before, the method of SPARCLE1 will be

\section{SPARCLE 2 model for participation} (Similar model for quality of life)

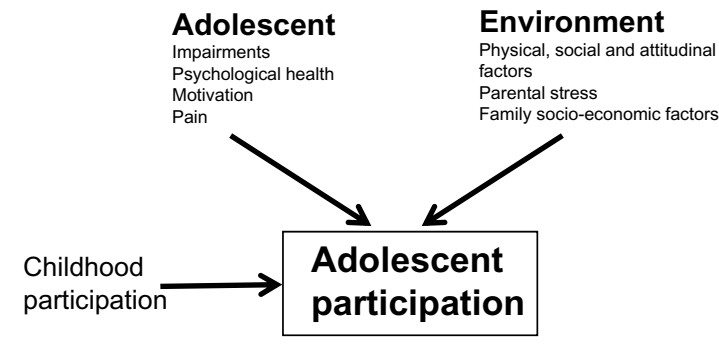

Figure 1 Model of predictors of adolescent participation 
used where a health professional who knows the child, such as General Practitioner or Paediatrician, will approach the family.

We will strive to approach the adolescents in such a way that they can make an informed decision about whether to join the study. For those under 16 years (18 years in France), parental consent must be obtained in addition to that of the adolescent. For those over 16, we will not seek parental consent but will take seriously a parent who did not want their child to join the study.

If the adolescent becomes distressed by questions on sensitive issues, the RA cannot provide support but will facilitate contact with general practitioner or psychological service.

If the RA is concerned that the adolescent might be being abused, action in a person over 18 must be with the adolescent's agreement. If under 18, the RA will first liaise with the scientific lead in each region to ensure statutory procedures are followed.

The safety of the RAs will be maximised by ensuring visits are to home or school; by providing a mobile phone and requiring the RA to tell the office their expected time of return.

The National Research Ethics Service, Newcastle and North Tyneside Research Ethics Committee, approved the project: 09/H0906/4.

\section{Dissemination}

The findings of the study will be disseminated in a range of formats:

- Academic publications. Our output from SPARCLE1 [11,23,30-47]demonstrates the importance we attach to this and our ability to deliver.

- Feedback to young people and parents, as already undertaken in SPARCLE1.

- Meetings of European Academy of Childhood Disability, Royal College of Paediatrics and Child Health and meetings around QoL and adolescence.

- An official report with executive summary which will be presented to National Governments, the European Commission and the European Parliament, as in SPARCLE1.

\section{Discussion}

This study will increase understanding of how to improve the life and health of disabled adolescents - a neglected group in which few epidemiological studies have been undertaken.

Health is a broad concept, defined by WHO [10] as a state of complete physical, mental and social wellbeing. This is especially relevant to disabled people who often have no disease and impairments that are relatively stable. Although much medical research aims to prevent disease and impairments and treat disease, for disabled people improved health may be only marginally influenced by medical intervention; participation in social and family life and effective transition to adulthood, which are important components of health, may respond more readily to social and environmental intervention.

The UN Conventions on Rights of the Child, and Rights of Persons with Disabilities recognise the rights of disabled children to participate fully in life and express their views. By capturing quality of life as a key outcome, our study will allow disabled adolescents a voice and findings should influence attitudes towards them.

In our earlier study of 8-12-year-old children with cerebral palsy, there were marked differences in child participation between countries, after controlling for severity of impairment. This suggests the environment is more facilitatory in some countries than others. If longitudinal analyses confirm these associations, they would provide strong evidence for advocacy and policy development in health, education and social sectors. Associations of participation and QoL with pain, psychological health and parental stress will also be studied; as all are amenable to intervention, results should inform trials of interventions.

\section{Appendix. Main findings of SPARCLE1 - Study of participation and quality of life of 8-12 year old Children with Cerebral Palsy Living in Europe The main findings to date are:}

1. Children with $\mathrm{CP}$ who were able to report their own QoL had, on average, similar QoL to children of the same age in the general population. Although some impairments were associated with lower QoL in some areas of life of the children with $\mathrm{CP}$, these factors accounted for less than $10 \%$ of the variation in QoL of disabled children and therefore their QoL must be largely determined by other factors such as those that influence QoL in non-disabled children.

2. Pain is common and significantly associated with lower QoL.

3. When the child's report of their QoL is compared to what their parents think it is, parents usually underestimate their child's QoL.

4. For children with intellectual impairment, parental reports indicate that pain is associated with poorer QoL on some domains; restricted mobility with reduced physical well being and autonomy. However restricted mobility and intellectual impairment were associated with better QoL on other domains. Parents who are more stressed tend to report poorer QoL in their child across all domains.

5. The participation of children with cerebral palsy is considerably lower than that of children in the general population. This is more pronounced for those with severe motor impairment; and for those with more 
impairments. Pain is also associated with reduced participation.

6. For children with similar levels of impairment, participation varies significantly between countries.

7. Children with cerebral palsy have more psychological problems than the general population. Among children with learning difficulties, these psychological problems are commoner in children with the milder physical impairments.

8. Parents of children with cerebral palsy experience more stress than parents in general. Stress tends to be greater for parents whose children have more severe cerebral palsy. Parental stress is associated with lower child-reported QoL on five of the ten QoL domains.

9. The seven EU countries in the study vary considerably in their attitudinal environment and in environmental law, regulation and social and physical provision for disabled children. These differences are summarised in a published report commissioned by the SPARCLE project.

10. An environmental questionnaire was developed. The degree to which families and their disabled children receive the environmental support they need varies greatly. Children with less need are more likely to have their needs met; and certain factors such as wheelchairs are provided much more often than for example communication aids. There is also striking variation across the European $\mathrm{EU}$ regions in the extent to which needed environmental features are available.

11. We think, though these analyses are not completed, that some aspects of the environment concerning adaptations, access to buildings, transport, schooling etc are are strongly associated with better participation; but effects on QoL are much weaker.

12. At the end of the home visit, we asked children to indicate on paper, confidentially and anonymously, what they felt about being asked all the questions; and what they thought about the research associate who visited them. Two centres did not administer it. Of 340 children who could complete the "smiley face" options, only 12 children were unhappy about being asked the questions and only four children were unhappy about the person who visited them.

\section{Competing interests}

The authors declare that they have no competing interests.

\section{Authors' contributions}

The protocol was developed and agreed jointly by the members of the SPARCLE group in a series of workshops. AFC and HOD drafted the manuscript. All members of the SPARCLE group contributed to the design of the study and this manuscript and all have approved the final manuscript.

\section{Acknowledgements}

*The SPARCLE group is: Allan Colver, Kathryn Parkinson and Heather Dickinson, Newcastle University, Newcastle, UK; Malin Carlsson, Göteborg University,
Göteborg, Sweden; Jackie Parkes, Queens University, Belfast, UK; Jérôme Fauconnier, Université Joseph Fournier, Grenoble, France; Alan Lyons, Enable Ireland, Cork, Ireland; Susan Michelsen, NIPH, University of Southern Denmark, Copenhagen, Denmark; Marco Marcelli, AUSL, Viterbo, Italy; Catherine Arnaud, INSERM, Toulouse, France; Ute Thyen, Luebeck, Germany

The study has been funded by:

UK and Ireland: Wellcome Trust WT 086315 A1A.

Germany: Medical Faculty of University of Luebeck E40-2009.

France: CNSA, INSERM, MiRe - DREES, IRESP.

Denmark: Ludvig and Sara Elsass Foundation: The Spastic Society; Vanforefonden.

Italy: Cooperativa Sociale "Gli Anni in Tasca", Viterbo; Fondazione Carivit, Viterbo.

Sweden: Göteborg University; Riksförbundet för Rörelsehindrade Barn och Ungdomar; Folke Bernadotte Foundation.

\section{Author Details}

${ }^{1}$ Institute of Health and Society, Newcastle University, Newcastle upon Tyne, UK and 2 James Spence Building, Royal Victoria Infirmary, Queen Victoria Road, Newcastle upon Tyne NE1 4LP, UK

Received: 21 April 2010 Accepted: 26 May 2010

Published: 26 May 2010

\section{References}

1. Sloper P, Turner S: Service needs of families of children with severe physical disability. Child Care Health Dev 1992, 18:259-282.

2. Michelsen SI, Uldall P, Kejs AMT, Madsen M: Education and employment prospects in cerebral palsy. Dev Med Child Neurol 2005, 47:511-517.

3. Michelsen SI, Uldall P, Hansen T, Madsen M: Social integration of adults with cerebral palsy. Dev Med Child Neurol 2006, 48:643-649.

4. Law M, Hanna S, King G, Hurley P, King S, Kertoy M, Rosenbaum P: Factors affecting family-centred service delivery for children with disabilities. Child Care Health Dev 2003, 29:357-366.

5. Oliver M: The Politics of Disablement London: Macmillan; 1990

6. World Health Organisation: International classification of functioning, disability and health. In Book International classification of functioning, disability and health WHO, Geneva; 2001.

7. World Health Organisation: World Health Organisation Classification of Functioning, Disability and Health. Children and Youth Version. In Book World Health Organisation Classification of Functioning, Disability and Health. Children and Youth Version WHO, Geneva; 2007.

8. Muldoon MF, Barger SD, Flory JD, Manuck SB: What are quality of life measurements measuring? BMJ 1998, 316:542-545.

9. Zekovic B, Renwick R: Quality of life for children and adolescents with developmental disabilities: review of conceptual and methodological issues relevant to public policy. Disabil Soc 2003, 18:19-34

10. WHOQOL: The World Health Organization quality of life assessment position paper from the World Health Organization. Soc Sci Med 1995 41:1403-1409.

11. Dickinson HO, Parkinson KN, Ravens-Sieberer U, Schirripa G, Thyen U, Arnaud C, Beckung E, Fauconnier J, McManus V, Michelsen SI, et al:: Selfreported quality of life of 8-12-year-old children with cerebral palsy: a cross-sectional European study. Lancet 2007, 369:2171-2178.

12. Fulginiti VA: What is pediatrics?: prenatal medicine to young adult care. Am J Dis Child 1992, 146:17-18.

13. Schidlow DV, Fiel SB: Life beyond pediatrics. Transition of chronically ill adolescents from pediatric to adult health care systems. Med Clin North Am 1990, 74:1113-1120.

14. Stevenson CJ, Pharoah PO, Stevenson R: Cerebral palsy--the transition from youth to adulthood. Dev Med Child Neurol 1997, 39:336-342.

15. Bowes G, Sinnema G, Suris JC, Buhlmann U: Transition health services for youth with disabilities: a global perspective. J Adolesc Health 1995, 17:23-31.

16. Intercollegiate Working Party on Adolescent Health: Bridging the gaps: health care for adolescents. In Book Bridging the gaps: health care for adolescents London: Royal College of Paediatrics and Child Health; 2003.

17. Ko B, McEnery $G$ : The needs of physically disabled young people during transition to adult services. Child Care Health Dev 2004, 30:317-323.

18. Blum RW: Overview of transition issues for youth with disabilities. Pediatrician 1991, 18:101-104. 
19. Hammal D, Jarvis S, Colver A: Participation of children with cerebral palsy is influenced by where they live. Dev Med Child Neurol 2004, 46:292-298

20. Beckung E, Hagberg G: Neuroimpairments, activity limitations, and participation restrictions in children with cerebral palsy. Dev Med Child Neurol 2002, 44:309-316.

21. Watson N, Shakespeare T, Cunningham-Burley S, Barnes C: Life as a disabled child: A qualitative study of young people's experience and perspectives. Department of Nursing Studies, University of Edinburgh: Economic and Social Science Research Council; 1999.

22. Houlihan CM, O'Donnell M, Conaway M, Stevenson RD: Bodily pain and health-related quality of life in children with cerebral palsy. Dev Med Child Neurol 2004, 46:305-310.

23. Mihaylov SI, Jarvis S, Colver A, Beresford B: Identification and description of environmental factors that influence participation of children with cerebral palsy. Dev Med Child Neurol 2004, 46:299-304.

24. Rosenbaum PL, Livingston MH, Palisano RJ, Galuppi BE, Russell DJ: Quality of life and health-related quality of life of adolescents with cerebral palsy. Dev Med Child Neurol 2007, 49:516-521.

25. Livingston MH, Rosenbaum PL, Russell DJ, Palisano RJ: Quality of life among adolescents with cerebral palsy: what does the literature tell us? Dev Med Child Neurol 2007, 49:225-231.

26. Bisegger C, Cloetta B, von Rueden U, Abel T, Ravens-Sieberer U: Healthrelated quality of life: gender differences in childhood and adolescence. Soz Praventivmed 2005, 50:281-291.

27. SCPE: Prevalence and characteristics of children with cerebral palsy in Europe. Dev Med Child Neurol 2002, 44:633-640.

28. Surman G, Bonellie S, Chalmers J, Colver A, Dolk H, Hemming K, King A, Kurinczuk JJ, Parkes J, Platt MJ: UKCP: a collaborative network of cerebral palsy registers in the United Kingdom. J Public Health (Oxf) 2006, 28:148-156.

29. Hemming K, Hutton $\mathrm{J}$, Colver A, Platt MJ: Regional variation in survival of people with cerebral palsy in the United Kingdom. Pediatrics 2005, 116:1383-1390

30. Colver A: Study protocol: SPARCLE - a multi-centre European study of the relationship of environment to participation and quality of life of children with cerebral palsy. BMC Public Health 2006, 6:105.

31. Dickinson H, Parkinson K, McManus V, Arnaud C, Beckung E, Fauconnier J, Michelsen SI, Parkes J, Schirripa G, Thyen U, Colver A: Assessment of data quality in a multi-centre cross-sectional study of participation and quality of life of children with cerebral palsy. BMC Public Health 2006, 6:273.

32. Arnaud C, White-Koning M, Michelsen SI, Parkes J, Parkinson K, Thyen U, Beckung E, Dickinson HO, Fauconnier J, Marcelli M, et al:: Parent-reported quality of life of children with cerebral palsy in Europe. Pediatrics 2008, 121:54-64.

33. Parkes J, White-Koning M, Dickinson HO, Thyen U, Arnaud C, Beckung E, Fauconnier J, Marcelli M, McManus V, Michelsen SI, et al: Psychological problems in children with cerebral palsy: a cross-sectional European study. J Child Psychol Psychiatry 2008, 49:405-413.

34. Michelsen SI, Flachs E, Uldall P. Eriksen E, McManus V, Parkes J, Parkinson $\mathrm{KN}$, Thyen U, Arnaud C, Beckung E, et al:: Frequency of participation of 812-year-old children with cerebral palsy; a multi-centre cross-sectional European study. Eur J Paediatr Neurol 2009, 13:165-177.

35. Dickinson $\mathrm{HO}$, Colver A: Quantifying the physical, social and attitudinal environment of children with cerebral palsy. Disabil Rehabil 2010 in press.

36. Lawlor K, Mihaylov S, Welsh B, Jarvis S, Colver A: A qualitative study of the physical, social and attitudinal environments influencing the participation of children with cerebral palsy in northeast England. Pediatr Rehabil 2006, 9:219-228.

37. McConachie H, Colver AF, Forsyth RJ, Jarvis SN, Parkinson KN: Participation of disabled children: how should it be characterised and measured? Disabil Rehabil 2006, 28:1157-1164.

38. McManus V, Michelsen S, Parkinson K, Colver A, Beckung E, Pez O, Caravale $B$ : Discussion groups with parents of children with cerebral palsy in Europe designed to assist development of a relevant measure of environment. Child Care Health Dev 2006, 32:185-192.

39. Tisdall K: National contextual factors affecting the lives of disabled children in Denmark, France, Germany, Ireland, Italy, Sweden and UK (England and Northern Ireland). Book National contextual factors affecting the lives of disabled children in Denmark, France, Germany, Ireland,
Italy, Sweden and UK (England and Northern Ireland) 2006, 1: [http:// www.ncl.ac.uk/sparcle/Publications files/WebVol1.pdff. Newcastle: Newcastle University

40. Tisdall K: National contextual factors affecting the lives of disabled children in Denmark, France, Germany, Ireland, Italy, Sweden and UK (England and Northern Ireland). Book National contextual factors affecting the lives of disabled children in Denmark, France, Germany, Ireland, Italy, Sweden and UK (England and Northern Ireland) 2006, 2: [http:// www.ncl.ac.uk/sparcle/Publications files/WebVol2.pdf]. Newcastle: Newcastle University

41. White-Koning M, Arnaud C, Bourdet-Loubere S, Bazex H, Colver A Grandjean H: Subjective quality of life in children with intellectual impairment - how can it be assessed? Dev Med Child Neurol 2005, 47:281-285

42. White-Koning M, Arnaud C, Dickinson HO, Thyen U, Beckung E, Fauconnier J, McManus V, Michelsen SI, Parkes J, Parkinson K, et al. Determinants of child-parent agreement in quality-of-life reports: a European study of children with cerebral palsy. Pediatrics 2007, 120:e804-814

43. Young B, Rice H, Dixon-Woods M, Colver AF, Parkinson KN: A qualitative study of the health-related quality of life of disabled children. Dev Med Child Neurol 2007, 49:660-665.

44. Colver AF, Dickinson HO: Access of children with cerebral palsy to the physical, social and attitudinal environment they need: a crosssectional European study. Disabil Rehabil 2010 in press.

45. Erhart M, Ravens-Sieberer U, Dickinson HO, Colver A: Rasch measurement properties of the KIDSCREEN quality of life instrument in children with cerebral palsy and differential item functioning between children with and without cerebral palsy. Value Health 2009 in press.

46. Carlsson M, Olsson I, Hagberg G, Beckung E: Behaviour in children with cerebral palsy with and without epilepsy. Dev Med Child Neurol 2008, 50:784-789

47. McCullough N, Parkes J, White-Koning M, Beckung E, Colver A: Reliability and validity of the Child Health QuestionnairePF-50 for European children with cerebral palsy. J Pediatr Psychol 2009, 34:41-50.

48. Green H, McGinnity A, Meltzer H, Ford T, Goodman R: Mental Health of Children and Young People in Great Britain 2004 London: Office for National Statistics; 2005

49. Centre for Longitudinal Studies: 2008 [http://www.cls.ioe.ac.uk/ publications.asp?section $=0001000100060001]$

50. Parkes J, White-Koning M, Dickinson HO, Thyen U, Arnaud C, Beckung E, Fauconnier J, Marcelli M, McManus V, Michelsen SI, et al:: Psychological problems in children with cerebral palsy: a cross-sectional European study. J Child Psychol Psychiatry 2008, 49(4):405-13.

51. Michelsen SI, Flachs E, Uldall P, Eriksen E, McManus V, Parkes J, Parkinson K, Thyen $U$, Arnaud C, Beckung E, et al:. Frequency of participation of 8-12year-old children with cerebral palsy; a multi-centre cross-sectional European study. Eur J Paediatr Neurol 2009, 13:165-77.

52. Loehlin J: Latent variable models Hillsdale, NJ, Erlbaum Publishers; 1992.

53. Williams JR: The promise and limits of international bioethics: lessons from the recent revision of the Declaration of Helsinki. J Int Bioethique 2004, 15:31-42.

54. Ravens-Sieberer U, Gosch A, Rajmil L, Erhart M, Bruil J, Duer W, Auquier P, Power M, Abel T, Czemy L, et al.: KIDSCREEN-52 quality-of-life measure for children and adolescents. Expert Review of Pharmacoeconom Outcomes Res 2005, 5:353-364.

55. Thelen E, Smith L: A dynamic systems approach to the development of cognition and action Cambridge, Massachusetts: MIT Press; 1994

56. Morgan G, Leech N, Barrett K, Busch-Rossnagel N, Harmon R: The dimensions of mastery questionnaire (manual) Colorado State University; 2000

57. Manuel J, Naughton MJ, Balkrishnan R, Paterson Smith B, Koman LA Stress and adaptation in mothers of children with cerebral palsy. $J$ Pediatr Psychol 2003, 28:197-201.

58. Goodman R: Psychometric properties of the Strengths and Difficulties Questionnaire. J Am Acad Child Adolesc Psychiatry 2001, 40:1337-1345.

59. Molenberghs G: What to do with missing data? J R Stat Soc A 2007 , 170:861-863.

60. Rotnitzky A, Robins JM, Scharfstein DO: Semiparametric regression for repeated outcomes with nonignorable nonresponse. J Am Stat AssoC 1998, 93:1321-1339. 
61. Kline RB: Principles and practice of structural equation modeling Second edition. New York, Guilford Press; 2005.

62. Byrne BM: Structural equation modeling with LISREL, PRELIS and SIMPLIS: basic concepts, applications and programming Mahwah, NJ, Erlbaum; 1998.

63. Dunn G, Everitt B, Pickles A: Modelling covariances and latent variables using EQS London: Chapman \& Hall/CRC; 1993.

64. Lepage C, Noreau L, Bernard PM, Fougeyrollas P: Profile of handicap situations in children with cerebral palsy. Scand J Rehabil Med 1998, 30:263-272.

65. Noreau L, Lepage C, Boissiere L, Picard R, Fougeyrollas P, Mathieu J, Desmarais G, Nadeau L: Measuring participation in children with disabilities using the Assessment of Life Habits. Dev Med Child Neurol 2007, 49:666-671.

66. Abidin R: Parenting Stress Index Professional Manual 3rd edition. USA: Psychological Assessment Resources Inc; 1995.

67. Landgraf J, Abetz L, Ware JE: Child Health Questionnaire (CHQ): a User's Manual, Second Printing Boston, MA: HealthAct; 1999.

68. Varni JW: Pediatric Pain Questionnaire - Teen Form. In Book Pediatric Pain Questionnaire - Teen Form City: LICENSOR Mapi Research Trust; 1998.

\section{Pre-publication history}

The pre-publication history for this paper can be accessed here: http://www.biomedcentral.com/1471-2458/10/280/prepub

doi: $10.1186 / 1471-2458-10-280$

Cite this article as: Colver et al., Study protocol: Determinants of participation and quality of life of adolescents with cerebral palsy: a longitudinal study (SPARCLE2) BMC Public Health 2010, 10:280

Submit your next manuscript to BioMed Central and take full advantage of:

- Convenient online submission

- Thorough peer review

- No space constraints or color figure charges

- Immediate publication on acceptance

- Inclusion in PubMed, CAS, Scopus and Google Scholar

- Research which is freely available for redistribution

Submit your manuscript at www.biomedcentral.com/submit
C) Biomed Central 